\title{
OS ESTUDOS DA SIGNIFICAÇÃO NO BRASIL
}

\author{
EDUARDO GUIMARÃES \\ DL-IEL/LABEURB-NUDECRI (UNICAMP)
}

\begin{abstract}
RESUME Ce texte retrace un parcours historique des études de la signification au Brésil en s'organisant autour de deux éléments. Le premier est le rapport du sujet à la question du sens chez les auteurs évoqués; le second est la manière dont les études de la signification affectent directement l'histoire de la grammaire au Brésil. Au travers de ce parcours sont essentiellement étudiés quatre moments depuis la fin du XIXe siècle. Nous aborderons donc, tout d'abord, le travail de Pacheco Silva Jr à partir de ses Notions de Sémantique, puis celui de Said Ali, par la relation des Moyens d'Expression et Altérations Sémantiques dans son travail grammatical. Nous apportons ensuite une réflexion sur la stylistique et l'œuvre grammaticale de Mattoso Câmara. Le texte conclut par l'approche d'aspects des études de la signification dans les années 70 du XXe siècle.
\end{abstract}

Constituir uma história dos estudos da significação no Brasil é, de um certo modo, refazer a história dos estudos lingüísticos no Brasil. É colocar em cena algo que sempre operou e que as histórias oficiais da lingüística têm sido incapazes de considerar. Estou falando, por exemplo, da relação constitutiva que os estudos da significação têm com os estudos lingüísticos em geral e do lugar que aí têm as concepções de sujeito, que atuam de modo significativo desde o século XIX no Brasil. A História dos estudos da significação é, na história brasileira, por exemplo, inseparável de uma história da gramática.

A história da lingüística no Brasil, como em geral, não conta uma história da semântica (ou conta quase nada). Quanto a isso poderíamos lembrar o texto "A Filologia Portuguesa no Brasil" de Antenor Nascentes, publicado em 1930, e o texto de Mattoso Câmara (1966) "Os Estudos de Português no Brasil", publicado em 1969 e retomado em Dispersos. Neles não há nenhuma referência aos estudos semânticos no Brasil. Em seu "Perspectivas Gerais" Coseriu (1976) reduz a história da semântica na América Latina a algo como um parágrafo. A. Naro (1976) em "Tendências Atuais da Lingüística e da Filologia no Brasil" aí inclui uma parte sobre uma história da semântica. Trata de posições formais ou estruturais dos estudos semânticos dos anos 70 do século passado.

\footnotetext{
${ }^{1}$ Texto inicialmente apresentado no VI Colóquio Internacional Luso-Brasileiro nos EUA em 1966.
} 


\section{HISTÓRIA DAS IDÉIAS LINGÜÍSTICAS: PROCEDIMENTOS}

Vou pensar a história da ciência como uma reflexão sobre os modos de agenciamento enunciativo que constituem as cenas enunciativas específicas desta ciência.

Quanto à enunciação do dizer científico, não podemos deixar de registrar que ele se dá num espaço enunciativo marcado pela predominância da chamada língua padrão. Ou seja, a ciência se caracteriza como um dizer que se formula na relação das línguas nacionais. E nesta medida, ela é determinada, por uma relação específica entre falantes e línguas, por uma relação com o Estado.

Por outro lado, fazer a história de uma ciência, de uma disciplina, envolve ser possível fazer um relato de uma construção conceitual. Para mim fazer este relato é buscar no dizer do cientista, ou seja, na sua construção argumentativa, um relato que aí se constitui pelo próprio modo como o cientista é tomado por um agenciamento enunciativo específico.

\section{UMA HISTÓRIA BRASILEIRA DA GRAMÁTICA}

Logo no início do "Prólogo à 1" Edição" de sua Gramática Expositiva, Eduardo Carlos Pereira (1907) diz²: "Depois que Júlio Ribeiro imprimiu nova direção aos estudos gramaticais, romperam-se os velhos moldes, e estabeleceu-se largo conflito entre a escola tradicional e a nova corrente".

Este enunciado, que faz parte da apresentação, como sabemos, de uma das gramáticas mais usadas no ensino no Brasil até o final dos anos 50 do século XX, é um enunciado próprio do modo do relato. Ele estabelece um antes e um depois: antes de Júlio Ribeiro, depois de Júlio Ribeiro. E mais: este enunciado nos conta dois novos acontecimentos sucessivos da história da gramática no Brasil, posteriores à nova direção dada por Júlio Ribeiro: o rompimento com os velhos moldes e o estabelecimento de um conflito entre a escola tradicional e a nova corrente.

E Júlio Ribeiro é aqui a metonímia de sua Grammatica Portugueza de 1881. Por esta metonímia fica posto como acontecimento, que faz uma passagem, esta gramática. E que passagem é esta? A passagem de uma gramática portuguesa para uma gramática brasileira. E ao colocar Júlio Ribeiro e não o nome da obra para referir o acontecimento da publicação da gramática, este relato põe a questão da autoria brasileira ${ }^{3}$ da gramática como própria desta história brasileira.

Eduardo Carlos Pereira fala, assim - ele não a reivindica -, numa história brasileira da gramática. E isto se faz na medida em que seu enunciado sequer refere a gramática portuguesa, ou sequer arrola nesta pequena seqüência de acontecimentos um acontecimento português. Todos os acontecimentos aí relatados se dão no Brasil. $\mathrm{O}$

${ }^{2}$ Retomo aqui parte do que apresentei em "Uma Poética da Adição", Congresso sobre Política Lingüística na América Latina, UBA, Buenos Aires, 1997b.

${ }^{3}$ Sobre este aspecto da gramatização brasileira ver "O Estado, A Gramática, a Autoria" (Orlandi, 1997). 
rompimento com os velhos moldes e o estabelecimento do conflito entre a tradição e o novo se dá entre gramáticas brasileiras que são publicadas, segundo a narrativa, a partir de Júlio Ribeiro. Sua própria gramática se dá como "objeto" nesta história, fazendo das outras gramáticas incluídas no seu relato, também, "objeto" desta história.

O que quero dizer aqui é que Eduardo Carlos Pereira se conta enquanto gramático, numa história brasileira do pensamento gramatical.

Deste modo, se podemos dizer que no final do século XIX, a partir dos anos 80, deu-se o processo de gramatização ${ }^{4}$ brasileira do Português ${ }^{5}$, podemos observar que, pouco tempo depois, os gramáticos no Brasil já se significam numa história brasileira da gramática.

Esta história da gramática no Brasil, tal como temos mostrado em trabalhos anteriores, pode sinteticamente ser apresentada como segue:

a) A gramatização brasileira ${ }^{6}$ constitui-se na Segunda metade do século XIX, a partir dos anos 80, e tendo a Grammatica Portugueza de Júlio Ribeiro (1881) como marco deste início ${ }^{7}$.

b) A partir da Gramática Expositiva de E.C.Pereira 1907) já podemos registrar, como vimos acima, as formulações de um pensamento gramatical numa história brasileira $^{8}$.

c) Nesta história brasileira é especialmente importante para mim a formulação, por Said Ali, no início de sua Gramática Secundária (de 1924), do lugar de uma gramática descritiva não-normativa. Lugar preenchido pela primeira vez por Estrutura da Língua Portuguesa de Mattoso Câmara ${ }^{9}$, em 1970.

\section{A SEMÂNTICA E A PRIMEIRA CONSTITUIÇÃO DO PENSAMENTO LINGÜÍSTICO NO BRASIL}

A questão da significação e a constituição da semântica se coloca no Brasil na mesma época em que a gramatização brasileira do Português se põe em curso pela mão destes mesmos gramáticos.

Podemos tomar este fio da história a partir de Pacheco Silva Jr. Ele, na sua Grammatica Historica da Lingua Portugueza, de 1879, trata da mudança de sentido

\footnotetext{
${ }^{4}$ Segundo Auroux, gramatização é o processo que conduz a descrever e a instrumentar uma língua na base de duas tecnologias, que são ainda hoje os pilares de nosso saber metalingüístico: a gramática e o dicionário" (Auroux, 1992).

${ }^{5}$ Sobre a gramatização brasileira do português ver Guimarães (1994) e Orlandi e Guimarães (1998). Sobre aspectos da história da Gramática no Brasil ver também Guimarães (1997a , 1997b , 1999a, 1999b, 2000)

${ }^{6}$ Sobre gramatização cf. Auroux (1992). Sobre a gramatização brasileira cf. (Guimarães (1994), Orlandi (1997, 2000) e Orlandi e Guimarães (1998).

${ }^{7}$ Sobre isso ver Guimarães (1994) e Orlandi e Guimarães (1998).

${ }^{8}$ Coloquei esta questão inicialmente em Guimarães (1997a e 1997b).

${ }^{9}$ Quanto a isso cf. Guimarães (1999a, 2000).
} 
das palavras e, na segunda edição de sua Grammatica da Lingua Portugueza ${ }^{10}$ (em coautoria com Lameira de Andrade), em 1894, inclui nela uma seção de semântica (estudo da mudança de sentido das palavras). Além disso é sua a primeira obra de semântica no Brasil. Seu Noções de Semântica é de 1903, publicado depois de sua morte. Mas o mais importante na obra de Pacheco é que do estudo das mudanças de sentido de sua Grammatica Histórica em 1879 (que inclui a semântica na gramática) ao Noções de Semântica, publicado em 1903, vemos operar um pensamento lingüístico que se estabelece e modifica, exatamente na medida em que a semântica toma corpo. Pacheco parte de uma posição naturalista, enunciada no início de sua gramática histórica: "A sciência da linguagem faz parte da historia natural: é um conjunto organico cujo estudo pertence ás sciencias biologicas, e mais propriamente á anthropologia” (p. III). A esta posição, se opõe, num certo sentido sua última obra. Em Noções de Semântica encontramos: "somos hoje accordes com os últimos pareceres philologicos em que a linguagem deve fazer parte das investigações históricas e não das sciências naturais" (Silva Jr, 1903, p. 12). Com esta posição parece que o semanticista Pacheco Silva do presente, marcado pelo hoje e pelos últimos pareceres philologicos, rompe com o gramático histórico (o naturalista de antes). Mas não me parece ser esta uma boa interpretação. Para mim, a presença, desde a Grammatica Histórica, das preocupações semânticas no pensamento de Pacheco Silva é o elemento que nos permite interpretar o deslocamento de sua posição e considerar o seu interesse.

Para caracterizar melhor o Noções de Semântica, retomo a afirmação do autor segundo à qual ele está de acordo com a posição dos que consideram que a linguagem deve "fazer parte das investigações históricas e não das sciências naturaes". Tem-se aqui, de algum modo, uma referência a Bréal ${ }^{11}$, sem citá-lo. Pacheco Silva nos diz no prefácio da obra ter conhecido o Éssai de Sémantique só depois de concluído seu trabalho. Diz, no entanto, que fez mudanças na sua obra a partir do conhecimento do Éssai. Esta referência a Bréal interessa também por outros aspectos. Em seguida à afirmação de que considera a lingüística nos estudos históricos, Pacheco diz discordar daqueles que julgam que não se devem usar as metáforas orgânicas para falar da linguagem. Mais uma vez uma referência a $\mathrm{Bréal}^{12}$ sem citá-lo. Só que agora como discordância. Assim Pacheco argumenta a favor da atualidade de seu trabalho e mantém o espaço de uma reflexão que vinha realizando a partir de outras bases.

Pacheco se coloca, então, na posição de considerar a linguagem como histórica, mas, ao mesmo tempo, de considerar que a lingüística não precisa se desfazer de sua remissão às ciências naturais, onde deve ou pode buscar as metáforas para construir seus conceitos. A linguagem passa a ser um objeto das ciências humanas, mas analisado a partir de um discurso das ciências naturais, mais notadamente da biologia. E aqui temos uma inversão, é a gramática que se inclui na semântica. Diz ele no final da introdução de Noções de Semântica: "A semântica é da maior importância para o estudo da evolução lingüística: a grammatica, codificação das leis promulgadas pelo

${ }^{10}$ Silva, Jr, M.P. e Andrade, L (1887)

${ }^{11}$ Lembro aqui formulações de Bréal (1897) ao comentar La vie des mots de A. Darmesteter (1887).

12 Também aqui pode-se lembrar as críticas de Bréal ao naturalismo ao comentar o livro de Darmesteter e condenar as metáforas biológicas. 
povo, consiste em grande parte em phenomenos semânticos" (Silva Jr., 1903, p. 17). Ou seja, o gramatical é semântico.

No interior do litígio amigável com Bréal, acima exposto, podemos observar que a analogia é, para Pacheco Silva, a razão das mudanças lingüísticas. Segundo ele "o povo, diante da necessidade de exprimir idéias novas, em lugar de criar novas palavras, serve-se de termos conhecidos mudando-lhes ou renovando-lhes os sentidos" (Silva Jr, 1903, p. 19). E faz isso tomando como "modelo" elementos existentes na própria língua. Ele diz, por outro lado, que as mudanças de sentidos se dão através dos tropos e figuras que se originam na ação da analogia (idem, p. 30). É nessa perspectiva que se deve, por exemplo, entender o que diz no capítulo cinco em que trata da adaptação e assimilação: "a palavra não fica estreitamente prisioneira da hereditariedade. Pode modificar-se, em certa medida, sob a influência de condições externas” (idem, p. 620. Para ele as mudanças se dão pela ação da analogia por influência de condições externas.

E como agem estas condições externas? Pela ação do povo, para quem estas condições externas impõem necessidades novas. Neste ponto é que podemos ligar as duas pontas deste percurso: de um lado a gramatização brasileira do Português e de outro a constituição da semântica no Brasil.

A necessidade de estudar o léxico no Brasil está ligada em Pacheco Silva, como de resto em vários lingüistas e lexicógrafos brasileiros da época ${ }^{13}$ a problemas práticos de descrição motivados por um projeto intelectual de estabelecer, em seguida à Independência, a especificidade do Português no Brasil. Estes problemas práticos, por outro lado, colocam em cena as mudanças de sentido das palavras como maneira de descrever as diferenças entre Brasil e Portugal. Os brasileirismos, que ele apresenta ao final de sua gramática histórica, são um modo de descrever estes aspectos, já numa linha de filiação vinda do Visconde de Pedra Branca ${ }^{14}$.

Como caracterizar o papel da noção de povo em Pacheco Silva? É preciso levar em conta diferenças devidas às condições de suas formulações. Se tomamos sua posição na sua Grammatica da Lingua Portugueza (que inclui os brasileirismos, agora no início da obra) tem-se o povo enquanto sujeito nacional que deve aprender a língua sob o signo da correção. Em outras palavras, o sujeito coletivo é determinado enquanto identificado pela ação da instituição escolar.

Se consideramos, por outro lado, o próprio modo como este sujeito é constituído no interior do Noções de Semântica, podemos observar que se trata em certa medida de um sujeito psicológico coletivo. Tomemos, por exemplo, uma seqüência no capítulo sobre analogia, em que ele formula e especifica a ação do povo: "O povo desconhece o sentido dos suffixos, mas pelo uso contínuo das palavras com elles formadas, crêa outros derivados directamente analogos, e muitas vezes inconscientemente. Os eruditos formaram altruismo, optimismo (...); o povo, sem cogitar da significação do suffixo, foi com elle creando outros vocabulos (sebastianismo, florianismo, burrismo, caftismo, etc)" (idem p. 28).

${ }^{13}$ Sobre a história do dicionário no Brasil ver Nunes (1996)

${ }^{14}$ Seu estudo sobre os Brasileirismos é de 1824-25. Tendo sido escrito, como sabemos, em Francês. Sobre estas questões ver Orlandi e Guimarães (1998). 
Nas condições brasileiras a construção do pensamento de Pacheco Silva coloca em cena um sujeito social remetido ao Estado e à constituição da Nação. E isto significa afirmar que, embora não formulado diretamente, o pensamento de Pacheco Silva inclui um compromisso político específico, uma formulação de política específica sobre a língua portuguesa no Brasil.

Este percurso de Pacheco Silva tem como base uma concepção do sujeito da linguagem. Em verdade, de um sujeito da língua, o povo, que se formula desde sua Grammatica Historica, preparando as condições da inversão que o fez passar do biologismo ao histórico, da inclusão da semântica na gramática, à inclusão da gramática na semântica.

Desta maneira o deslize do Homem (a pessoa) para o Povo, como fundamento da configuração do sujeito em Pacheco Silva, dá novas condições que se agregam aos outros movimentos do pensamento do autor de Noções de Semântica ${ }^{15}$.

Pode-se dizer que o projeto de descrever uma língua para construí-la como língua nacional estabeleceu estas novas condições que criaram um percurso muito particular.

A constituição deste sujeito coletivo sócio-político se fundamenta numa ética que fica tensionada entre um princípio ético da unidade, uma ética do Estado que busca a homogeinização (que inclui a semântica na gramática), e um princípio ético da diferença, que pode abrigar os brasileirismos (e provincialismo), e que inclui a gramática na semântica ${ }^{16}$. Esta oscilação ética acompanha de uma certa forma uma oscilação teórica: aquela que o faz passar do biológico ao histórico, como concepção de linguagem, que corresponde a passar de uma gramática histórica, como forma de dizer o conhecimento, para uma semântica, na qual se apresenta de uma maneira direta o povo como sujeito da língua.

A passagem da enunciação da semântica como parte da gramática para a enunciação da gramática como parte da semântica tem, na obra de Pacheco Silva Jr., uma configuração enunciativa que se desloca de uma formulação naturalista para uma formulação histórica tendo como base a metaforização dos conceitos da primeira formulação pela segunda.

Interessa, de modo particular, o fato de ele considerar que o sujeito da linguagem, o povo, enquanto qualificado, sem que o autor o diga ou saiba, pelos "brasileirismos" que construiu na língua, é parte desta operação que transforma uma concepção constituída em bases biológicas em metáfora para constituir uma outra concepção, agora histórica.

Ou seja, a constituição do pensamento lingüístico de Pacheco Silva está diretamente relacionado a como a questão da significação aí opera, que história isto produz.

\footnotetext{
${ }^{15}$ Uma análise mais vagarosa desta questão pode ser vista em Guimarães (1999b).

${ }^{16}$ Sobre ética e linguagem ver, por exemplo, Auroux (1998) e Orlandi (1998).
} 


\section{SAID ALI SEMANTICISTA}

Meios de Expressão e Alterações Semânticas de Said Ali (1927) tem três partes. A primeira é um estudo sobre a significação que analisa o funcionamento de expressões que para o autor exprimem o sentimento, as intenções específicas de quem fala e expressões que ele chama de expressões de situação. Nas duas outras partes, Said Ali descreve mudanças de sentido (alterações semânticas) de palavras do português, e empréstimos, que ele chama de "Aquisições Novas-Estrangeirismos". A semântica era para ele, então, o estudo das mudanças de sentido das palavras, era uma semântica lexical, numa tradição tipicamente comparatista. O domínio da significação é para ele dividido em dois campos: um que estuda os meios de expressão, os aspectos psicológicos do uso da língua, e outro que estuda seus aspectos semânticos, as mudanças de sentido das palavras.

Esta divisão da obra não está sustentada em nenhum aparato teórico específico. $\mathrm{O}$ livro é dado como uno exatamente pela falta de um aparato teórico. Ou seja a língua é que se dá como lugar de unidade da descrição. A unidade do livro é que ele é um conjunto de descrições sobre a Língua Portuguesa. E um conjunto de descrições que sustentam, por exemplo, que a descrição de uma língua não pode ser reduzida a seus aspectos lógicos e gramaticais. Posição que aparece expressa no Prólogo da obra, como veremos melhor mais adiante.

Neste Prólogo Said Ali formula, por uma operação narrativa, de um lado a questão da norma, de outro a do sentido na relação com a gramática. Comecemos pela questão da norma. Diz-nos ele: "O lingüista de hoje investiga os fatos sem preocupar-se com a questão do que é ou deixa de ser correto. Em geral procuro seguir o mesmo rumo; mas as dúvidas dêsse gênero podem prender-se a questões de ordem mais elevada e aí encontrar solução. Outras vêzes, a documentação geralmente respeitada em que fundo os estudos dará a solução incidentemente" (p. II)

Este hoje relaciona-se, para opor-se, ao lingüista do passado que aparece articulado à questão do sentido e da gramática em "Acima do modo, antigo e exclusivista, de ver as cousas, está a indagação histórica. E a investigação da evolução dos fenômenos não se há de limitar às mudanças de fonemas e formas gramaticais, mas estender-se às expressões que com o tempo se foram trocando por outras. Entra-se no domínio da psicologia e da semântica.”(Ali, 1927)

Aqui o antigo data o passado do qual o hoje do presente do autor se distancia. Um hoje no qual o que interessa não é a correção ou não da expressão. Os trabalhos que se ocupam destes aspectos são assim postos no passado, mesmo que feitos naquele momento.

Se o passado é o antigo, é ele também que se ocupava "com a questão do que é ou deixa de ser correto". O antigo se caracteriza por uma visão limitada das questões de linguagem (nos termos de Said Ali, uma visão normativa). Romper esta limitação é incluir no campo das preocupações lingüísticas o psicológico e o semântico. Nesta medida, a consideração do sentido opera contra a redução da linguagem ao lógico e gramatical e em oposição ao normativo e ao purismo. 


\subsection{Um Sujeito Psicológico para a Linguagem}

A formulação do lugar do sujeito em Meios de Expressão e Alterações Semânticas se faz, desde o primeiro enunciado do Prólogo, em "O homem normal exprime o que pensa e o que sente por meio da palavra, acompanhada ou desacompanhada de mímica e de gestos" (Ali, 1927, IX).

A palavra é aqui, numa linha de filiação por todos conhecida, instrumento da expressão do pensamento e do sentimento (o psicológico).

Ao formular as funções da linguagem, não como definição de linguagem, mas como ações do homem normal, fica posto que o sujeito da linguagem é o homem normal, enquanto ser que pensa e sente e que exprime o que pensa e o que sente. Assim o campo da significação aparece como o que é expresso pelo homem normal. E homem normal é parafraseado pelo próprio Said Ali, em outro momento, como Indivíduo ${ }^{17}$.

A entrada da significação coloca para a linguagem um sujeito psicológico (o indivíduo, homem normal) que faz com que o sentimento de quem fala seja significado no que diz, quando fala.

Se no hoje de Said Ali configura-se este sujeito da linguagem, a sua formulação opera sobre ele uma outra caracterização não menos importante do ponto de vista teórico. Nas sequências a seguir lemos: a)"uma cousa é dirigirmo-nos à coletividade, a pessoas desconhecidas de condições diversas, e que nos ouvem caladas; outra cousa é tratar com alguém de perto, falar e ouvir, e ajeitar a cada momento a linguagem em atenção a essa pessoa que está diante de nós, para que fique sempre bem impressionada com as nossas palavras" (idem, 30); b) (b.1) "todos estes recursos de linguagem nos acodem (...) (b.2) chamemos-lhes expressões de situação (...) (b.3) "porém nem este (ouvinte) nem o orador os analisam" (idem, 30).

Ao enunciar-se no nós de [a] e [b.1] o autor se significa como falante; ao enunciar-se no nós de [b.2] o autor significa o falante como lingüista. Ao mesmo tempo o autor enuncia da lugar do lingüista, sem as sobreprojeções acima quando se distancia das categorias de falante e ouvinte em [b.3]. Assim a escrituração enunciativa de Meios de Expressão não só constitui um sujeito psicológico da linguagem, mas identifica este sujeito com o lugar do lingüista, que a par de constituir um distanciamento para descrever deve procurar descrever as próprias representações do falante que também é. Cabe ao lingüista, sujeito de conhecimento, reproduzir no plano da análise as próprias operações do indivíduo falante. Operação que se realiza no esforço de uma descrição da língua no espaço formulado como científico, como não-normativo.

\subsection{Um Sujeito Social para a Língua}

Na parte sobre Alterações Semânticas de Meios de Expressão, Said Ali procura descrever as mudanças de sentido de um conjunto de palavras, tomadas uma a uma, como sendo um processo da língua fora do sujeito. Ele nos diz: a) "Nas seguintes páginas exponho as alterações semânticas por que passaram várias expressões da língua

17 "Nos casos apontados, a causa perturbadora da boa estrutura oracional é a precipitação no falar: reside no próprio indivíduo que expõe suas idéias (idem, p. 23). 
portuguesa, mostro as épocas em que as acepções diferiram das atuais e explico, sempre que posso, as causas das mudanças" (Ali, 1927, p. 55); b) "Há extensão ou alargamento quando um termo de sentido especial passa a ter sentido geral" (idem, ibidem); c) "Quando um termo se usa com várias acepções diz-se que há polissemia" (idem, p. 57)

Estas seqüências formulam o funcionamento da língua na relação consigo mesma, embora no se usa de [c] vejamos insinuar-se o sujeito falante.

No entanto, nos diz também: "Mudanças definitivas de sentido podem ser determinadas pela metonímia, pela analogia, pela eufemismo, pela degradação" (idem, p. 56)

Onde faz entrar a analogia como causa de mudança.

Assim, se o semântico é enunciado como um processo sem sujeito, este se repõe como psicológico através do uso e da analogia e assim da memória. Ele mesmo nos diz na sua Gramática Histórica: "Não dissocio do homem pensante e da sua psicologia as alterações porque passou a linguagem em tantos séculos. É a psicologia elemento essencial e indispensável à investigação de pontos obscuros. As mesmas leis fonéticas seriam inexistentes sem os processos da memória e da analogia. Até o esquecimento, a memória negativa, é fator, e dos mais importantes, na evolução e progresso de qualquer idioma.

Adotado semelhante método de pesquisa, adquiriu o livro certo aspecto de lexeologia semântica, ou, se preferirem, de semântica lexeológica, destoando assim de vetusto sistema de classificação.”(Ali, 1931, p. 7)

Mas há uma outra formulação, nem tanto lateral, que também inclui nesta parte a questão do sujeito. Ao iniciar a descrição das mudanças semânticas da primeira palavra que considera ("anatomia") diz: "Do termo científico anatomia cedo se apoderou o vulgo para lhe atribuir sentido depreciativo. Usava-o de preferência no plural" (idem, p. 58).

A escrituração enunciativa da sequência opõe "termo científico" a "vulgo", o que faz aparecer "científico" como oposto a "vulgar" e "cientista" como oposto a "vulgo". Por esta via formula-se uma distinção de tipos de sujeito: "os cientistas" e "o vulgo", e isto faz entrar em cena toda uma tipologia de lugares sociais do sujeito, na qual está "pessoas educadas", etc.

É interessante ver que a entrada deste sujeito social põe de pronto a questão da correção e da normatividade no uso da língua, por um viés em que Said Ali aparece na posição de quem a considera. Normatividade que fica remetida a estas distinções sociais estratificadas. Num texto em que Said Ali procura falar de uma língua sem sujeito irrompe este sujeito social estratificado.

Se o estudo da significação em Said Ali guarda, no que ele chama de semântica, um quadro comparatista, e nele um sujeito social estratificado, seu estudo dos aspectos psicológicos amplia o espaço do indivíduo que fala enquanto sujeito da linguagem.

Se voltamos ao gramático Said Ali diremos que sua gramática secundária, que é uma gramática normativa, prática nos seus termos, é uma gramática da Língua Nacional, para a formação intelectual e identificação do povo brasileiro (sujeito da língua nacional). Ao lado disso sua Gramática Histórica é mais uma descrição da história da língua portuguesa, considerando que uma língua muda porque não há 
linguagem sem sujeito, sem sentido, como vimos, acima, pela citação do que nos coloca na sua Gramática Histórica

É interessante ver como a divisão conceitual, no tratamento do sentido, entre o psicológico e o semântico é produto da divisão do sujeito da linguagem (o indivíduo), ou da língua-idioma (o povo).

O que estamos vendo é que a questão da significação não opera nestes autores (Pacheco Silva e Said Ali) como algo lateral. Ao contrário, as questões semânticas e do sujeito da linguagem são centrais no modo de construção do pensamento lingüístico, articulando-se, sempre, com o gramatical e, nesta articulação, constitui um modo específico de dizer o lingüístico. E aqui, pelas próprias relações já colocadas sobre a história da gramática, chegamos novamente a Mattoso Câmara, para quem a gramática tem na estilística sua complementaridade.

\section{O ESTILÍSTICO E O GRAMATICAL}

Mattoso coloca a questão do estilo no interiror de sua reflexão sobre as funções da linguagem na formulação de Bühler, e nesta linha diz: "Como se define formalmente, porém, a grande parcela do estilo que assim escapa ao conceito saussuriano da língua? Evidentemente, por uma linguagem que transcende do plano intelectivo para carrear a emoção e a vontade.” (Mattoso, 1953, 13)

E diz um pouco mais adiante: "A língua absorve, destarte, uma carga afetiva que se infiltra em seus elementos e os transfigura por assim dizer. O adjetivo belo, por exemplo, tem uma significação intelectiva e encerra um julgamento acerca do ser a que é aplicado; traduz uma determinada representação desse ser (um bosque, digamos), distinta da que transmitiria denso, ou grande, ou verde. Até aí, estamos na língua em senso estrito; mas dela transborda o ato lingüístico, que é a enunciação do termo em dadas circunstâncias, porque nele se revela o entusiasmo de quem assim nos fala ou ainda o seu esforço para nos fazer participar desse entusiasmo"(idem, 14).

Em seguida Mattoso liga estas considerações às funções da manifestação psíquica e do apelo. E antes de concluir a parte do livro sobre o conceito de estilo diz: "Se estamos certos nesta ordem de idéias, chegamos à conclusão de que o estudo do estilo nos dá a contraparte lingüística que nos faltava. Com ele temos a linguagem distribuída em torno dos dois pólos da representação mental pura e da expressão psíquica lato sensu na Dupla Função de que nos fala Paulhan sob os nomes de linguagem significativa e linguagem sugestiva"(XLIII-17ss. in Mattoso, 14).

E conclui esta parte dizendo:

"A estilística vem complementar a gramática." (idem, 14)

Assim, ao tratar do estilo, vemos que para Mattoso as questões do sujeito entram em consideração quando se pensam os aspectos psicológicos envolvidos na situação de enunciação, segundo as circunstâncias desta situação. Deste modo a questão do sujeito aparece como contraparte da gramática, do sistemático e formal da linguagem, mas como algo também da língua (não deixa de lembrar Bally, que ele cita em vários momentos). 
É interessante observar como o corte que coloca o psicológico, produzido por Mattoso, difere do de Said de Ali em Meios de Expressão e Alterações Semânticas num aspecto: o corte de Said Ali divide o campo da significação em semântica e estudo dos aspectos psicológicos, o corte de Mattoso divide o campo dos estudos da linguagem em gramatical e estilístico (psicológico).

\section{UMA HISTÓRIA NÃO CONTADA}

Num importante texto sobre o pensamento de Said Ali, e mais uma vez um encontro de Mattoso e Said Ali como personagens de uma mesma história, diz-nos Mattoso Câmara (1961): (Por outro lado) tinha uma aguda sensibilidade pela língua cotidiana viva, e muitos dos seus estudos (especialmente em Meios de expressão $e$ alterações semânticas) fazem um exegese gramatical e estilística dos diálogos constantes de romances modernos - de Júlio Diniz, de Camilo, de Eça de Queirós, de Machado de Assis, - em contraste com a tendência da filologia do seu tempo, só preocupada com a linguagem formalística e um tanto convencional dos textos expositivos em que o escritor abandona a espontaneidade da reação lingüística para se exprimir meditadamente, na base de um raciocínio gramatical que se lhe impõe como um cerimonial de etiqueta. Isso lhe permitiu perceber e apreciar o fenômeno fonético da “entonação' ou da modulação da voz na frase (num excelente artigo de Dificuldades da Língua Portuguesa ${ }^{18}$ ), em cujo estudo foi um verdadeiro pioneiro para o português e bem merece ter continuadores" (Mattoso, 1961, p. 189).

Por outro lado, no artigo, a que me referi no início, dedicado aos "Estudos de Português no Brasil", de 1966, posterior ao artigo sobre Said Ali, acima citado, encontramos uma referência ao autor de Meios de Expressão e Alterações Semânticas. Nela diz-nos Mattoso, e aqui, diferentemente da forma do presente com que enuncia seus comentários acima sobre Said Ali, a narrativa se dá nas formas do passado: "Já Said Ali concentrou-se em certos problemas específicos de categorias gramaticais em português, como a conceituação do chamado "condicional", que ele interpretou fundamentalmente como um "futuro do pretérito", a função da partícula se na caracterização da forma verbal, o valor dos tempos compostos do auxiliar ter em locução com um particípio perfeito, que ele considerou primordialmente como uma expressão do aspecto "perfectivo" (Ali, 1930, 1931)" (Mattoso, 1966).

Mattoso fala em seguida dos estudos sobre infinitivo do autor de Meios de Expressão para finalizar suas observações sobre Said Ali como segue (note-se que se mantém a forma do passado perfeito): "Teve ainda o mérito de debater o papel da intonação na frase portuguesa; fê-lo filologicamente, por assim dizer, na base de diálogos de romances modernos (especialmente os de Julio Diniz), mas de qualquer maneira pôs em foco o problema (Ali 1930, $11 \mathrm{segs)"} \mathrm{(Mattoso,} \mathrm{1966).}$

O que se nota de imediato é que ele não inclui aqui o que chamou, no trabalho de 1961, os estudos estilísticos de Said Ali. Ou melhor, aquilo que incluiu destes estudos

\footnotetext{
${ }^{18}$ Ali (1908)
} 
ele qualificou, neste último caso, de estudos filológicos sobre a intonação. É bem verdade que o filológico é modalizado por um "por assim dizer". Deste modo, no momento em que está apresentando uma história global dos Estudos do Português no Brasil não dá lugar para a estilística, e nesta medida não dá lugar para os estudos sobre o sujeito e o sentido. Ou seja, nesta medida, Mattoso fala da posição que é própria das histórias da lingüística no Brasil: a que desconhece a existência consistente de estudos sobre a significação e a questão do sujeito na linguagem. Estudos que, como vimos, ele próprio faz.

Mas este esquecimento produzido pelo discurso de uma história oficial sobre os estudos de linguagem no Brasil, pelo qual Mattoso é tomado, precisa ser intepretado à luz de dois modos de narrar. No primeiro caso, quando fala da estilística, Mattoso relata o trabalho de Said Ali com formas do imperfeito e do presente. No segundo, quando esquece as questões de sentido, o relato está no passado na forma perfectiva. Ou seja, quando ele é tomado pela posição oficial da história brasileira da lingüística, ele próprio esquece aquilo que este discurso insiste em esquecer; quando ele traz para o presente de sua enunciação o relato do trabalho de Said Ali, o real da descrição de questões de sentido e do sujeito que aí se encontram é formulado. Em outras palavras, há aí duas histórias pelo mesmo autor: aquela que, da posição de uma história oficial, se atém ao estabilizado e, de outro lado, aquela que se conta pela reflexão específica que se possa fazer a partir de uma posição teórica particular e que, assim, procura desautomatizar os lugares fixados de legitimidade.

\section{SÉCULO XX, ANOS 70}

O percurso histórico que vai de Pacheco Silva, passa por Said Ali e chega a Mattoso Câmara, desloca a discussão lingüística no Brasil da questão da língua nacional para a questão da língua. $\mathrm{E}$ isto funda outro espaço de formulações para $\mathrm{o}$ pensamento lingüistico brasileiro. E é assim que chegamos à década de 70 do século passado, inaugurada pela publicação do Estrutura da Língua Portuguesa. A obra de Mattoso Câmara é um momento decisivo nesta inflexão. De um certo modo o pensamento lingüístico brasileiro se desvencilha, então, do século XIX.

A década de 70 do século XX é o momento em que no Brasil os estudos sobre significação se intensificam, estando neles incluídos trabalhos fortemente ligados à consideração das questões do sujeito.

Há, neste momento, como estudos da significação: a) os estudos estruturais que realizavam suas análises sêmicas; b) as análises semióticas do texto; c) os estudos enunciativos ou pragmáticos do enunciado; d) os estudos discursivos. Com exceção das análises sêmicas estruturais, as demais posições passaram a incluir, cada uma a seu modo, a questão do sujeito no estudo da significação.

Estes trabalhos constituem parte fundamental dos estudos de linguagem no Brasil naquele momento. Tanto que nas décadas de 80 e 90 do século passado, os estudos lingüísticos se desenvolveram diretamente afetados pelo conhecimento que então se produziu no campo dos estudos da significação e da questão do sujeito na linguagem. 
Em torno de 1975, a produção brasileira marca este espaço de reflexão com um diálogo forte entre posições diferentes, de modo a estabelecer um campo de questões bem definidas, dando curso a um processo específico de contatos e debates teóricos que levaram a uma contribuição particular e relevante, em muitos casos, para a reflexão sobre a linguagem, a questão do sujeito e do sentido.

Havia, por outro lado, no Brasil, entre outras áreas de interesse, uma produção significativa no domínio da gramática, notadamente na sua formulação gerativotransformacional. Posição que também se desdobrou com consequiências nos últimos 20 anos.

O pensamento lingüístico brasileiro, que sempre discutiu a redução da linguagem ao gramatical, como estamos vendo, principalmente pela consideração dos aspectos da significação e do sujeito, instala, nos anos 70 do século XX, um debate forte entre o campo dos estudos da significação e o dos estudos gramaticais. E aqui vemos reaparecer, como debate amplo, os movimentos opostos de incluir a semântica na gramática, como o gerativismo, em contraposição ao que inclui a gramática no estudo da significação. Vou aqui passar por dois destes movimentos de centralidade da significação e do sujeito em dois estudiosos da linguagem cujas conseqüências nas suas própria obras nos anos seguintes e na lingüistica brasileira nos últimos 20 anos são marcantes.

Em O Intervalo Semântico, de $1977^{19}$, obra que é parte decisiva da construção da semântica argumentativa naquele momento, nos diz Carlos Vogt:

"A distinção língua/fala, competência/performance, assim como as dicotomias resultantes, são decisões teóricas.

O problema é que o segundo termo da distinção sempre recobriu um domínio negativo que a linguística, por não poder explicar, relegou à tarefa de outras ciências, que um dia o explicariam.

Mas como as demais ciências humanas, num movimento comum na direção da parente rica, tentaram também os caminhos da formalização, tais termos continuaram a esperar sua positividade e foram, na espera, ampliando uma região de inconveniências que a lingüística já não podia evitar.

E tais inconveniências eram tanto maiores quanto mais se mostravam com uma existência sistemática naquilo que a lingüística continuou chamando de seu objeto - a língua - e no qual tentava preservar a ausência de toda subjetividade, que é própria da linguagem.

É nesta linha de indagação que se pode sentir a importância dos trabalhos de Benveniste sobre a intersubjetividade na língua, o seu artigo sobre a natureza do pronomes, enfim, toda a secção dos Problèmes de Linguistique Générale intitulada "L'homme dans la langue". “(Vogt, 1977, p. 24)

Aqui pelo sempre recobriu, relegou, continuaram e já o autor insere sua argumentação no plano da história da lingüística. E aqui o autor conta uma história como forma de estabelecer uma positividade para sua análise. E que positividade ele constrói? Aquilo que não é sistema, não é gramática retorna sobre o próprio campo da

\footnotetext{
${ }^{19}$ A tese que resultou no livro é de 1975.
} 
lingüística que vai então disso se ocupar. A oposição ao gerativismo é global e se dá no plano da constituição do objeto.

Um outro aspecto: o "sempre recobriu" faz com que o pretérito de recobriu parafraseie o presente atemporal de são em "São decisões teóricas", mergulhando a atemporalidade da ciência no tempo da história. Neste movimento o autor inscreve a gramática na semântica, o que aparece expresso, por exemplo, em "Num estágio posterior talvez se possam pensar as formas de interação, de determinação recíproca destes domínios de representação simbólica e chegar-se, assim, àquilo que concebo coomo uma espécie de macrossintaxe das línguas naturais. Este seria o ponto teórico de interação, a que antes me referi. Ele deveria, então, ser concebido como região teórica de convergência da unidade da estrutura e da unidade de experiência, ou como o intervalo semântico, a região das significações intermediárias entre o dizer e o não dizer, local de explicitações não só dos processos de reprodução das significações, mas também de sua produção" (Vogt, 1980).

Em "Protagonistas do/no Discurso", Eni Orlandi (1978) ${ }^{20}$ diz: "Tratando-se da análise do discurso, já não se pode elidir os protagonistas da linguagem, que andaram desaparecidos por entre estruturas que se bastam a si mesmas e florestas sintáticas que os colocam em pé de igualdade, como réplicas da comunidade dos homens, no exercício de regras suficientemente gerais"(Orlandi, 1978, p. 31)

Nesta passagem, pela operação narrativa do andaram desaparecidos, Eni Orlandi coloca, pela análise de discurso, a questão do sujeito para os estudos da linguagem. E insere esta operação no debate direto com o estruturalismo e o gerativismo sintático.

Interessante operação. Ao afirmar a não consideração do sujeito no passado recente, afirma-se sua inclusão no presente, sem que isso seja uma afirmação de inexistência no presente do estruturalismo e do gerativismo, que ficam afirmados pela atemporalidade do discurso da ciência em "estruturas que se bastam a si mesmas e florestas sintáticas que os colocam em pé de igualdade, como réplicas da comunidade dos homens".

Ou seja, a consideração do sujeito, esquecida no passado pelo estruturalismo e gerativismo, ao ser colocada, trabalha diretamente o debate com estas mesmas posições.

Para aprofundar um pouco mais sua caracterização deste campo, retomemos o que diz, em "A sociolingüística, a Teoria da Enunciação e a Análise do Discurso", logo no início da seção "O Ponto de vista da análise de discurso": "Procura-se uma passagem entre enunciação e enunciado, entre língua e fala, etc. E talvez daí derive a dificuldade. Ao invés disso, poder-se-ia deslocar a distinção para o nível língua/discurso, como fez Pêcheux, considerando a língua como condição de possibilidade do discurso." (Orlandi, 1979, p. 45)

Temos também aqui uma operação narrativa que opera pelo funcionamento do “como $f e z$ Pêcheux". Este $f e z$ inscreve Pêcheux de um modo particular. Dá a ele um "lugar" anterior, uma posição fundadora. Isto inscreve a reflexão na história, "lembra" a história. Pêcheux não é só um "companheiro" de posição teórica.

\footnotetext{
${ }^{20}$ O texto original é de 1976, apresentado em uma mesa-redonda na Fista, Uberaba.
} 
A posição da autora de incluir nas suas considerações o histórico, que a leva à crítica das formulações de Benveniste, é responsável pela distinção que faz entre paráfrase e polissemia que será fundamental no decorrer de toda sua produção. Esta distinção aparece, na sequiência que segue, também no seu texto "Protagonistas do/no Discurso: "Se, de um lado, a força ideológica procura fixar a linguagem pela reiteração de sentidos, através do fechamento do texto, pelo mecanismo social da relação de forças e de sentido, e através da antecipação, por outro lado, a permanência do referente e dos agentes do discurso desafiam a linguagem em sua polissemia. Tensão mantida entre texto e contexto histórico-social: é este o novo visto como efeito de sentido." (Orlandi, 1978, 40)

Nesta passagem já está presente a questão da polissemia que a autora acresce tensionando a relação com a paráfrase, conceito descritivo central para a AD.

$\mathrm{O}$ que se vê é uma distinção de funcionamento de linguagem, de funcionamento discursivo, feita a partir de um conceito de polissemia que é definida pela exposição da linguagem ao real, ao histórico. Esta distinção será decisiva para várias de suas análises daquele momento ${ }^{21}$

Sobre os dois autores que acabamos de tratar é interessante registrar aqui os desdobramentos que advieram nos seus trabalhos nos últimos 20 anos. De um lado o desdobramento dos estudos enunciativos para o campo antropológico, que Cafundó. A África no Brasil (Vogt e Fry) mostra no caso de Carlos Vogt, por outro lado a formulação de contribuições teóricas específicas da Análise de Discurso no Brasil, como as presentes em As Formas do Silêncio e Interpretação de Eni Orlandi (1992, 1996).

\section{CONCLUSÃO}

Refazer a história da lingüística no Brasil, pela consideração do que os estudos da significação e do sujeito fazem neste quadro é também, pelo modo como a empreendemos, estabelecer uma história da constituição de conceitos.

Por esta via pudemos localizar alguns acontecimentos fundamentais desta história: a) um movimento que faz passar, em Pacheco Silva, do biológico ao histórico, como concepção de linguagem, que significa passar de uma gramática histórica, com forma de dizer o conhecimento, para uma semântica, na qual se apresenta de uma maneira direta o povo como sujeito da língua; isto corresponde a um movimento que vai da inclusão da semântica na gramática à inclusão da gramática na semântica; b) a formulação do lugar de uma gramática descritiva científica, não normativa, estabelecida por Said Ali, que vem relacionada com a consideração de um sujeito (psicológico) da linguagem; e c) o deslocamento das questões sobre a língua nacional para as questões da língua, que o trabalho de Mattoso Câmara claramente representa.

Nestes movimentos é interessante observar como a intensificação dos estudos da significação na década de 70 do século XX projeta todo um movimento de reflexão

${ }^{21}$ Análises sobre o discurso pedagógico (1978), discurso da mulher (1977), a questão da leitura (1982), o discurso religioso (1983). Estes textos foram posteriormente reunidos em Orlandi (1983). 
sobre a linguagem nos anos 80 e 90 do século passado. Ou seja, como estes estudos têm a ver com um contato muito particular entre os estudos de filosofia da linguagem, de pragmática, de enunciação e de análise do discurso no Brasil.

\section{BIBIOGRAFIA}

ALI, M.S. (1908). Dificuldades da Língua Portuguesa. Rio de Janeiro, Acadêmica, 1966. . (1924). Gramática Secundária da Língua Portuguesa. São Paulo, Melhoramentos, 1966. . (1927). Meios de Expressão e Alterações Semânticas. Rio de Janeiro, FGV, 1971. . (1931). Gramática Histórica da Língua Portuguesa. São Paulo Melhoramentos, 1966.

AUROUX, S. (1992). A Revolução Tecnológica da Gramatização. Campinas, Editora da Unicamp. (1998). La raison, le langage, et les normes. Paris, PUF.

BRÉAL, M. (1897). Ensaio de Semâtica. São Paulo, Pontes/Educ, 1992.

BUENO, F. da S. (1944). Gramática Normativa. São Paulo, Saraiva.

COSERIU, E. (1976). "Perspectivas Gerais". Tendências Atuais da Linguística e da Filologia no Brasil. Rio de Janeiro, Francisco Alves.

DARMESTETER, A (1887). La vie des mots. Paris, Hachette.

GUIMARÃES, E. (1994). "Sinopse dos Estudos do Português no Brasil. A Gramatização Brasileira”. Língua e Cidadania. Campinas, Pontes, 1996.

(1997a). "As Partes do Discurso na Gramática no Brasil. Um Consenso Normativo" Congresso Nacional da ABRALIN, Maceió.

(1997b). "Uma Poética da Adição". Congresso sobre Políticas Linguísticas na América Latina. Buenos Aires.

(1999a). "Uma Política da Língua em Said Ali. O Culto como Norma e a Recusa do Purismo". GT de Análise de Discurso da ANPOLL, Florianópolis. Revista da Anpoll, 8, 2000.

. (1999b). "Os Estudos da Significação no Brasil: uma História entre o Natural e o Histórico no século XIX". Línguas e Instrumentos Linguísticos, 3/4. Campinas, Pontes, 2000.

. (2000). "Entre o Estilítico e o Gramatical. Mattoso Câmara na História da Linguística no Brasil". Congresso "500 anos do Português no Brasil". Universidade de Évora.

MATtOSO CÂMARA Jr., J. (1953). Contribuição à Estilística Portuguesa. Rio de Janeiro, Ao Livro Técnico, 1977.

. (1961). "Said Ali e a Língua Portuguesa”. Dispersos. Rio de Janeiro, FGV, 1972.

(1966). “Os Estudos de Português no Brasil”. Dispersos. Rio de Janeiro, FGV, 1972.

(1970). Estrutura da Língua Portuguesa. Petrópolis, Vozes.

NARO, A.J. (1976). "Tendências Atuais da Lingüística e da Filologia no Brasil”. Tendências Atuais da Lingüística e da Filologia no Brasil. Rio de Janeiro, Francisco Alves.

NASCENTES, A. (1930). “A Filologia Portuguesa”. Estudos Filológicos. Rio de Janeiro, Civilização Brasileira.

NUNES, J.H. (1996). Discurso e Instrumentos Lingüísticos no Brasil: dos Relatos dos Viajantes aos Primeiros Dicionários. Tese de Doutorado. DL/IEL/UNICAMP. 
ORLANDI, E.P.(1978). "Protagonistas do/no Discurso". Foco e Pressuposição. Uberaba, Fista. . (1979). "A Sociolingüística, a Teoria da Enunciação e a Análise do Discurso". A Linguagem e seu Funcionamento. São Paulo, Brasiliense, 1983.

. (1983). A Linguagem e seu Funcionamento. Campinas, Pontes, 1997.

(1992). As Formas do Silêncio. Campinas, Editora da Unicamp.

(1996). Interpretação. Petrópolis, Vozes.

(1997). "O Estado, a Gramática, a Autoria”. Relatos, 4. Campinas. HIL.

(1998). "Ética e Política Lingüística". Línguas e Instrumentos Lingüísticos, 1. Campinas, Pontes.

(2000). "O Estado, a Gramática, a Autoria: Língua e Conhecimento Lingüístico". Linguas e Instrumentos Lingüísticos, 4/5. Campinas, Pontes.

ORLANDI, E.P. \& GUIMARÃES, E. (1998). "La Formation d'un Espace de Production Linguistique. La Grammaire au Brésil”. Langages, 130. Paris, Larousse.

PEREIRA, E.C. (1907). Gramática Expositiva. São Paulo, Nacional.

RIBEIRO, J. (1881). Grammatica Portugueza. São Paulo, Jorge Seckler.

SILVA Jr., M.P. (1879). Grammatica Historica da Lingua Portugueza. Rio de Janeiro, Francisco Alves. . (1903). Noções de Semântica. Rio de Janeiro, Francisco Alves.

SILVA Jr. M.P. \& ANDRADE, L. (1887). Grammatica da Lingua Portugueza. Rio de Janeiro, Francisco Alves, 1907.

VOGT, C. (1977). O Intervalo Semântico. São Paulo, Ática.

. (1980). "Por uma Pragmática das Representações". Linguagem, Pragmática e Ideologia. São Paulo, Hucitec.

VOGT, C. \& FRY, P. (1996). Cafundó. A África no Brasil. Campinas, Editora da Unicamp/Companhia das Letras. 